\title{
Microwave-Assisted One-Pot Synthesis of Symmetrical 4H-Pyran-4-ones
}

\author{
Firouz Matloubi Moghaddam, * Ghasem Rezanejade Bardajee and Hossein Ismaili \\ Sharif University of Technology, Department of Chemistry, PO Box 11365- 9516, Tehran, Iran
}

\begin{abstract}
Descrevemos um procedimento simples, rápido, eficiente e benigno para a síntese assistida por microondas, sem o uso de solvente, de 4-piranonas simétricas na presença de ácido polifosfórico ou pentóxido de fósforo. Diversas 4-piranonas foram preparadas por esse método simples e rápido.
\end{abstract}

We report a simple, fast, efficient and benign procedure for solvent-free microwave-assisted one-pot synthesis of symmetrical $4 \mathrm{H}$-pyran-4-ones in the presence of polyphosphoric acid or diphosphorous pentoxide. Various $4 H$-pyran-4-ones were prepared using this very simple and fast green protocol.

Keywords: cyclization, 4H-pyran-4-one, acid anhydride, synthetic methods, microwave irradiation

\section{Introduction}

Six-membered heterocyclic compounds containing oxygen such as $4 H$-pyran-4-ones ( $\gamma$-pyrones) constitute an important class of biologically active natural and synthetic products, playing a fundamental role in bioorganic chemistry and continue to attract interest. ${ }^{1}$ A large number of natural products containing a $\gamma$-pyrone unit have been isolated which show interesting biological activities. ${ }^{2-5}$ For example Phenoxan, a naturally occurring heterocyclic compound, was isolated from a soil microorganism and discovered to have anti-HIV activity. ${ }^{6}$ The structure of phenoxan, determined by a combination of proton/carbonNMR and high-resolution mass spectrometry, revealed the presence of a substituted pyran-4-one attached to an oxazole (Figure 1). Phenoxan is closely related to other microbial metabolites that contain a pyran-4-one system.

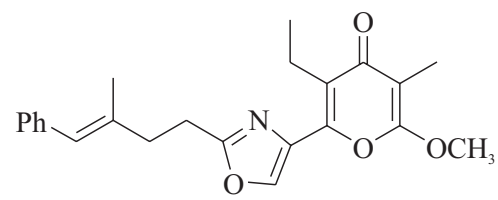

Figure 1. The structure of phenoxan.

Various methods are reported for the synthesis of $\gamma$ pyrone compounds. Some of the best known methods for the synthesis of $\gamma$-pyrone derivatives are: cyclization

*e-mail: matloubi@sharif.edu of $\beta$-dicarbonyl compounds, ${ }^{7}$ reaction of ynamines with diketens,${ }^{8}$ reaction of $\mathrm{N}, \mathrm{N}$-diethyl-aminophenylacetylene with $\mathrm{CO}_{2},{ }^{9}$ synthesis from other heterocyclic compounds such as furans, ${ }^{10}$ pyrane-2-one,${ }^{6}$ oxazoles $^{11}$ and carbohydrates. ${ }^{12}$

Considerable attention is paid to the simplification or improvement of existing methods widely used in the manufacture of pharmaceutical substances. Microwaveinduced reactions have already made an enormous impact in modern science. The employment of microwave irradiation (MW) to accelerate chemical reactions is now common practice.

Polyphosphoric acid and diphosphorous pentoxide are used extensively in organic synthesis and both are very strong dehydrating agents. For example, polyphosphoric acid was employed as a catalyst by many groups in the synthesis of various $\gamma$-pyrones. ${ }^{13-15}$

Due to the importance of $\gamma$-pyrones, there are a lot of publications related to the synthesis and applications. Although several methods have been reported for the synthesis of $\gamma$-pyrone compounds from different starting materials, still remains a great demand for the introduction of efficient, simple and more practical methods. Some of the reported procedures for the synthesis of $\gamma$-pyrones have certain limitations such as low yields, harsh reaction conditions, longer reaction times and costly reagents as well as inconvenience in handling the reagents. Here we report a rapid, simple and efficient method for the synthesis of symmetrically 
substituted $\gamma$-pyrones from acid anhydrides, carboxylic acids and ketones in the presence of polyphosphoric acid or diphosphorous pentoxide and under solvent free microwave irradiation.

\section{Results and Discussion}

In a typical procedure, a mixture of propionic anhydride $(2 \mathrm{mmol})$ and polyphosphoric acid (2 $\mathrm{g})$ was subjected to microwave irradiation (for 2 minutes) to afford the desired $\gamma$-pyrone (72\% yield). The obvious merit of this preparation lies in its simplicity and short reaction time as compared to other methods. The reaction then was applied to a variety of aliphatic acid anhydrides and carboxylic acids (Scheme 1). The results are summarized in Table 1.

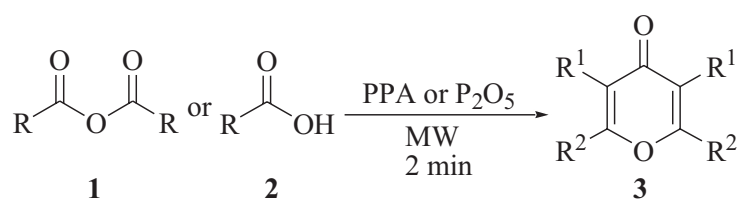
a ) $\mathrm{R}=\mathrm{Me}$
b) $\mathrm{R}=\mathrm{Et}$
c ) $\mathrm{R}=\mathrm{Pr}$
d ) $\mathrm{R}=\mathrm{Bu}$
e ) $\mathrm{R}=$ Pentyl
a ) $\mathrm{R}^{1}=\mathrm{H}, \mathrm{R}^{2}=\mathrm{Me}$
b) $\mathrm{R}^{1}=\mathrm{Me}, \mathrm{R}^{2}=\mathrm{Et}$
c) $\mathrm{R}^{1}=\mathrm{Et}, \mathrm{R}^{2}=\mathrm{Pr}$
d) $\mathrm{R}^{1}=\mathrm{Pr}, \mathrm{R}^{2}=\mathrm{Bu}$
e) $\mathrm{R}^{1}=\mathrm{Bu}, \mathrm{R}^{2}=$ Pentyl

Scheme 1.

Homologous carboxylic acids and acid anhydrides up to hexanoic gave the corresponding $\gamma$-pyrones in practical yields. Acid anhydrides are more reactive than carboxylic acids and their yields are better (Table 1). For larger aliphatic chains, the yields are lower (Table 1, entries 9, 10). Arylsubstituted pyrones could not be made efficiently from phenyl or nitrophenyl acetic acid. Furthermore, diphosphorus pentoxide was also used as a medium for $\gamma$-pyrone synthesis from aliphatic acid anhydrides under microwave irradiation (Table 1). All attempts at the synthesis of $\gamma$-pyrones from carboxylic acids in the presence of diphosphorus pentoxide failed. In the presence of diphosphorus pentoxide, the yields are decreased from acetic anhydride to hexanoic anhydride (Table 1, entries 1, 3, 5, 7, 9).

Additionally, microwave-assisted reaction of methylene ketones with carboxylic acids and their anhydrides in polyphosphoric acid were investigated (Scheme 2). Ketones condensed with carboxylic acids or acid anhydrides in the presence of polyphosphoric acid under microwave irradiation to give the desired $4 \mathrm{H}$-pyran-4-ones. The generality of the reaction has been shown by using different substitutions and the results are summarized in Table 2. Our investigations showed that acid anhydrides are more reactive than carboxylic acids producing higher yields (Table 2).

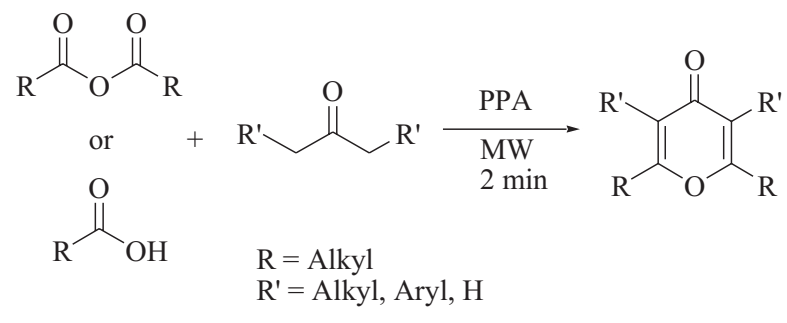

Scheme 2.

\section{Conclusion}

We developed a new, simple and very fast method for the one-pot preparation of symmetrical $\gamma$-pyrones via condensation of acid anhydrides and carboxylic acids in the presence of polyphosphoric acid or diphosphorous pentoxide under microwave irradiation. The generality of the method have been extended for the synthesis of various substituted $\gamma$-pyrones in a green solvent free condition.

\section{Experimental}

The chemicals used in the synthesis of all $\gamma$-pyrones were obtained from Merck Chemical Company and were used without further purification.

The products gave satisfactory all spectroscopic data. IR spectra were taken as thin films for liquid compounds and as $\mathrm{KBr}$ pellets for solids on a Nicolet spectrometer (Magna 550). The microwave oven used for this work was ETHOS-MR $\left(800 \mathrm{~W}, 180^{\circ} \mathrm{C}\right)$ at $2450 \mathrm{MHz}$. A Bruker (DRX-500 Avance) NMR was used to record the NMR spectra. All NMR spectra were determined in $\mathrm{CDCl}_{3}$ at ambient temperature. Melting points were determined on a Buchi B540 apparatus.

\section{General procedure for microwave irradiation}

A mixture of anhydride acid $(2 \mathrm{mmol})$ and polyphosphoric acid $(2 \mathrm{~g})$ or diphosphorous pentoxide (2 g) subjected to microwave irradiation (2 minutes) to give the desired $\gamma$-pyrone. The cooled mixture was diluted with ice-water, and continuously extracted with chloroform for several times. The combined organic phase was dried over anhydrous $\mathrm{MgSO}_{4}$ and evaporated under vacuum. The residue was purified by sublimation (3a), column chromatography or PTLC on silica gel.

Selected ${ }^{1} \mathrm{H}$ NMR data $^{13-15}$

2,6-Dimethyl-4H-pyran-4-one (3a)

${ }^{1} \mathrm{H} \mathrm{NMR} \mathrm{(500} \mathrm{MHz,} \mathrm{CDCl}_{3}$ ): $\delta 2.29\left(\mathrm{~s}, 6 \mathrm{H}, 2 \mathrm{CH}_{3}\right)$, 6.1 (s, 2 H, H-3, H-5). 
Table 1. Synthesis of $\gamma$-pyrones from carboxylic acids and acid anhydrides in the presence of polyphosphoric acid or diphosphorous pentoxide under microwave irradiation

\begin{tabular}{|c|c|c|c|c|}
\hline Entry & Substrate (1 or $\mathbf{2})$ & Product (3) & Yield/(\% $)^{\mathrm{a}, \mathrm{b}}$ & Yield $/(\%)^{\mathrm{a}, \mathrm{c}}$ \\
\hline 1 & & & 75 & 63 \\
\hline 2 & & & 71 & - \\
\hline 3 & & & 72 & 60 \\
\hline 4 & & & 68 & - \\
\hline 5 & & & 65 & 58 \\
\hline 6 & & & 60 & - \\
\hline 7 & & & 61 & 56 \\
\hline 8 & & & 55 & - \\
\hline 9 & & & 56 & 52 \\
\hline 10 & & & 44 & - \\
\hline
\end{tabular}

${ }^{a}$ All yields refer to isolated products. The products were characterized by $\mathrm{mp}, \mathrm{IR},{ }^{1} \mathrm{H}$ NMR, and their physical data were similar to those previously reported; ${ }^{13-15}$ bPolyphosphoric acid as a medium; ${ }^{\mathrm{c}}$ Diphosphorous pentoxide as a medium.

\section{2,6-Diethyl-3,5-dimethyl-4H-Pyran-4-one (3b)}

${ }^{1} \mathrm{H}$ NMR (500 MHz, $\left.\mathrm{CDCl}_{3}\right): \delta 1.26(\mathrm{t}, J 7.6 \mathrm{~Hz}, 6 \mathrm{H}$, $\left.2 \mathrm{CH}_{3}\right), 1.99$ (s, $\left.6 \mathrm{H}, 2 \mathrm{CH}_{3}\right), 2.64(\mathrm{q}, J 7.6 \mathrm{~Hz}, 4 \mathrm{H}, 2$ $\mathrm{CH}_{2}$ ).
3,5-Diethyl-2,6-dipropyl-4H-pyran-4-one (3c)

${ }^{1} \mathrm{H}$ NMR (500 MHz, $\left.\mathrm{CDCl}_{3}\right): \delta \quad 0.97$ (t, $6 \mathrm{H}, J 7.4 \mathrm{~Hz}, 2$ $\left.\mathrm{CH}_{3}\right), 1.055$ (t, $\left.J 7.5 \mathrm{~Hz}, 6 \mathrm{H}, 2 \mathrm{CH}_{3}\right), 1.63-1.71\left(\mathrm{~m}, 4 \mathrm{H}, 2 \mathrm{CH}_{2}\right)$, $2.42\left(\mathrm{q}, J 7.5 \mathrm{~Hz}, 4 \mathrm{H}, 2 \mathrm{CH}_{2}\right), 2.51\left(\mathrm{t}, J 7.4 \mathrm{~Hz}, 4 \mathrm{H}, 2 \mathrm{CH}_{2}\right)$. 
Table 2. Microwave-assisted synthesis of $\gamma$-pyrones from ketones and carboxylic acids or their anhydrides in the presence of polyphosphoric acid

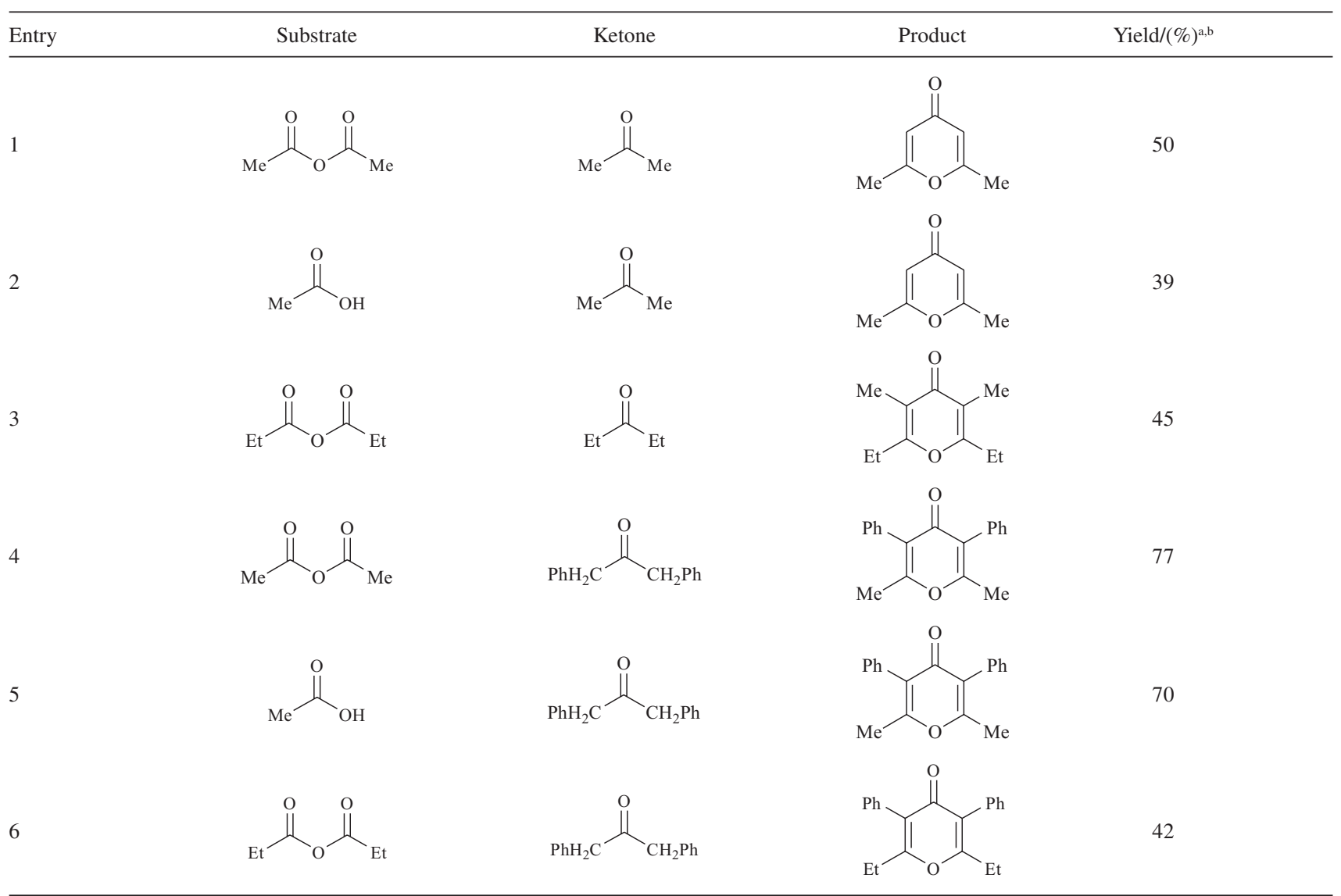

${ }^{a}$ All yields refer to isolated products. The products were characterized by mp, IR, ${ }^{1} \mathrm{H}$ NMR, and their physical data were similar to those previously reported; ${ }^{13-15}$ b The microwave irradiation time for all reactions is 2 minutes.

2,6-Dimethyl-3,5-diphenyl-4H-pyran-4-one (Table 2, entry 4)

${ }^{1} \mathrm{H} \mathrm{NMR}\left(500 \mathrm{MHz} \mathrm{CDCl}_{3}\right): \delta 2.31\left(\mathrm{~s}, 6 \mathrm{H}, 2 \mathrm{CH}_{3}\right)$, 7.29-7.45 (m, $10 \mathrm{H}, \mathrm{Ar})$.

\section{References}

1. Abe, I.; Oguro, S.; Utsumi, Y.; Sano, Y.; Noguchi, H.; J. Am. Chem. Soc. 2005, 127, 12709; Sibi, M. P.; Zimmerman, J.; J. Am. Chem. Soc. 2006, 128, 13346.

2. Puerta, D. T.; Mongan, J.; Tran, B. L.; McCammon, J. A.; Cohen, S. M.; J. Am. Chem. Soc. 2005, 127, 14148.

3. Pinto, M. M. M.; Sousa, M. E.; Nascimento, M. S.; J. Curr. Med. Chem. 2005, 12, 2517.

4. Salvatore, M. J.; Hensens, O. D.; Zink, D. L.; Liesch, J.; Dufresne, C.; Ondeyka, J. G.; Jurgens, T. M.; Borris, R. P.; Raghoobar, S.; Mccauley, E.; Kong, L.; Gartner, S. E.; Koch, G. E.; Pelaez, F.; Diez, M. T.; Cascales, C.; Martin, I.; Polishook, J. D.; Balick, M. J.; Beck, H. T.; King, S. R.; Hsu, A.; Lingham, R. B.; J. Nat. Prod. 1994, 57, 755.
5. Morisaki, K.; Ozaki, S.; Chem. Pharm. Bull. 1996, 44, 1647.

6. Garey, D.; Ramirez, M. L.; Gonzales, S.; Wertsching, A.; Tith, S.; Keefe, K.; Pena, M. R.; J. Org. Chem. 1996, 61, 4853.

7. Morris, J.; Luke, G. P.; Wishka, D. G.; J. Org. Chem. 1996, 61, 3218.

8. Ficini, J.; Genet, J. P.; Bull. Soc. Chim. Fr. 1974, 2086.

9. Ficini, J.; Pouliquen, J.; Tetrahedron Lett. 1972, 1131.

10. Matsumura, Y.; Shirai, B.; Maki, T.; Itakura, Y.; Kodera, Y.; Tetrahedron Lett. 1998, 39, 2339.

11. Grigg, R.; Jackson, J. L.; J. Chem. Soc. 1970, 552.

12. Beving, H. F. G.; Theander, O.; Acta Chem. Scand. B 1975, 24 , 577; Tajima, K.; Tetrahedron Lett. 1986, 27, 6095.

13. Letsinger, R. L.; Jamison, J. D.; J. Am. Chem. Soc. 1961, 83, 193.

14. Letsinger, R. L.; Kolewe, O.; J. Org. Chem. 1961, 83, 2993.

15. Mullock, E. B.; Suschitzky, H.; J. Chem. Soc. (C) 1967, 828.

Received: January 12, 2007 Web Release Date: August 15, 2007 